\title{
Los inicios del juego de lotería en Colombia: entre la suerte, el control social y el beneficio público*
}

\begin{abstract}
Resumen
El presente artículo indaga sobre el funcionamiento del juego de lotería en Colombia desde los finales del periodo de dominio hispánico, el proceso de Independencia y los primeros años de vida republicana. La metodología implica un estudio descriptivo y cualitativo basado en la consulta de fuentes primarias de la época. Se observa que en el antiguo régimen español y en el sistema republicano la lotería estuvo a cargo de instancias oficiales, quienes hicieron de este sistema, no un asunto filantrópico como se habían propuesto inicialmente, sino un proceso para cubrir las escasas arcas estatales.
\end{abstract}

Palabras clave: Nuevo Reino de Granada, Colombia, siglos XVIII y XIX, juego, proceso aleatorio, ocio, entretenimiento.

Referencias para citar este artículo: PITA PICO, Roger (2017). "Los inicios del juego de lotería en Colombia: entre la suerte, el control social y el beneficio público". En Anuario de Historia Regional y de las Fronteras. 22 (1). pp. 169-192.

Fecha de recepción: 31/03/2016

Fecha de aceptación: 5/07/2016

Roger Pita Pico: Magíster en Estudios Políticos de la Pontificia Universidad Javeriana. Especialista en Política Social. Politólogo de la Universidad de los Andes. Miembro de Número de la Academia Colombiana de Historia. Director de la Biblioteca Eduardo Santos. de la Academia Colombiana de Historia. Correo electrónico: rogpitc@hotmail.com.

\footnotetext{
${ }^{*}$ El presente artículo hace parte de un proyecto de investigación que de manera independiente adelanta el autor sobre Ocio, vida social y juegos de azar en Colombia: continuidades y rupturas de la Colonia a la República.
} 


\title{
The Beginnings of Lottery Game in Colombia: Among Luck, Social Control and Public Benefit
}

\begin{abstract}
Summary:
This article investigates the operation of lottery game in Colombia since the end of the Hispanic domain period, the process of Independence and the first years of republican life. The methodology involves a descriptive and qualitative study based on consultation of primary sources of that time. It is noticed that in the old Spanish regime and the Republican lottery system was in charge of official agencies who made this system, not a philanthropic matter as they had originally proposed, but a process to cover the few state coffers.
\end{abstract}

Keywords: New Kingdom of Granada, Colombia, Eighteenth and Nineteenth Centuries, Game, Random Process, Leisure, Entertainment.

\section{Os inicios do jogo de loteria na Colombia: entre a sorte, o controle social e o beneficio público}

\begin{abstract}
Resumo:
$O$ artigo presente indaga sobre o funcionamento do jogo de loteria na Colombia desde o final do período de domínio hispânico, o processo de Independencia e os primeiros anos da vida republicana. A metodologia implica um estudo descritivo e qualitativo baseado na consulta de fontes primarias da época. Observa-se que no antigo regime espanhol e no sistema republicano a loteria esteve a cargo de instancias sociais que não fizeram desse sistema um assunto filantrópico como se havia proposto inicialmente, senão um processo para cobrir os escassos cofres estatais.
\end{abstract}

Palavras-chave: Novo Reino da Granada, Colombia, séculos XVIII e XIX, jogo, processo aleatório, ócio, entretenimento. 


\section{Introducción}

La lotería se puede describir como un juego público, una modalidad de rifa en la que se premian con diversas cantidades varios billetes o boletas sacados al azar. Sus orígenes se remontan a Venecia del siglo XV. En España la primera lotería de carácter permanente y con premios en metálico se estableció en el reinado de Carlos III a través de la Orden del 30 de septiembre de 1753 y su propósito era destinar las utilidades para el socorro de instituciones benéficas ${ }^{1}$. Hacia 1800 se prohibieron los juegos de lotería en cafés y casas públicas, con lo cual el gobierno asumió el total monopolio de esta actividad. Paulatinamente aumentó la circulación de manuales matemáticos sobre el funcionamiento del juego y métodos para acertar, así como también debates morales sobre este tipo de apuestas ${ }^{2}$.

En los dominios hispanoamericanos, la lotería fue introducida también por esos años. La primera se creó en la ciudad de Lima bajo el aval del virrey Conde de Superunda y su objetivo era financiar la reconstrucción del hospital San Bartolomé ${ }^{3}$ En Nueva España la lotería fue instaurada en 1770 por el virrey marqués de Croix bajo una nueva modalidad consistente en la emisión de boletas divididas en décimos. El argumento esgrimido para autorizar este juego legal era que ayudaba a contener la inclinación hacia los juegos de suerte prohibidos ${ }^{4}$. Es decir, se concibió la lotería como una honesta opción de juego que aliviaría las urgencias del Real erario sin que representara un peligro para el patrimonio económico de los vasallos.

La presente investigación tiene por objeto indagar sobre las características y el impacto del juego de lotería durante sus inicios en Colombia. Por un lado, se intenta demostrar cómo se constituyó en una alternativa oficial de juego legal con mayores posibilidades de control social y, por el otro, en una nueva oportunidad del Estado para alimentar sus arcas. Además, examinar las continuidades y rupturas que se pudieron registrar entre las postrimerías del dominio hispánico, el convulsionado periodo de Independencia y los albores de la etapa republicana.

En realidad, aunque en las últimas décadas ha surgido el interés por el estudio de los juegos de azar dentro del marco de la historia social, particularmente el tema de las loterías ha sido muy poco abordado por la historiografía nacional, con alusiones bibliográficas muy cortas y fragmentarias. Por ello, la idea es profundizar en el análisis con base en fuentes documentales de archivo, informes de gobierno, compendios legales, crónicas y periódicos de la época.

\footnotetext{
${ }^{1}$ Enciclopedia Universal Ilustrada Europeo-Americana, t. XXXI (Barcelona: Hijos de J. Espasa Editores, 1933), p. 299.

${ }^{2}$ Lucena Giraldo, Manuel. 82 objetos que cuentan un país. Una historia de España (Madrid: Editorial Taurus, 2015), pp. 265-266.

${ }^{3}$ Bendezú Velarde, José. "Loterías: una alternativa para financiar los fondos para la educación”, en Revista de la Facultad de Ciencias Económicas, vol. V, núm. 19, Lima: Universidad Nacional Mayor de San Marcos, 2001, p. 186.

${ }^{4}$ Cordoncillo, José María. "La Real Lotería en Nuevas España”, en Anuario de Estudios Americanos, vol. XVIII, núm. 196, Sevilla, Escuela de Estudios Hispano-americanos, 1961, pp. 198-199.
} 
En tiempos del dominio hispánico existía una amplia gama de juegos. Entre los más preferidos figuraban los naipes y los dados que por lo general eran objeto de prohibiciones aunque solían practicarse en espacios ocultos. Proliferaron además juegos de carácter público que requerían del permiso de las autoridades y de controles a las apuestas como el bis bis $s^{5}$, el truco o billar, los bolos y la oca, entre otros. Desde el siglo XVII se incrementaron los espacios especiales para la práctica de juegos legales, obviamente supeditados a una serie de requisitos como la expedición de una licencia.

La condena de las autoridades a los juegos era porque inducían a la ociosidad, al apasionamiento o vicio, al desmoronamiento de las fortunas y al abandono del trabajo y de las obligaciones familiares. Las autoridades civiles y eclesiásticas implementaron medidas dirigidas a estrechar el control y la vigilancia y eso se vio reflejado en un incremento de la reglamentación en la segunda mitad del siglo XVIII, teniendo como desafío remediar el grave problema de la relajación de las costumbres ${ }^{6}$.

Por ser catalogada como un juego de azar, la lotería suscitaba diversos sentimientos como la tensión y la incertidumbre bajo el anhelo de una jugosa y repentina ganancia. Hasta antes de ser reglamentada y administrada por el Estado colonial español, la lotería se jugaba en espacios privados y fue severamente perseguida por las autoridades. Hacia el año de 1800, por ejemplo, en la villa de Medellín quedó proscrito este juego por los desórdenes sociales y los problemas económicos que causaba ${ }^{7}$.

Al quedar bajo el manejo estatal, la lotería reviste otras connotaciones y rasgos que la diferencian de otros juegos de azar. Si bien el Estado mantenía una importante participación a través de la renta obtenida del estanco de los naipes, para el caso de las loterías se observa una mayor injerencia oficial no solo en el proceso de organización sino también en los sorteos y entrega de premios. Era un juego supervisado por las autoridades y realizado en lugares previamente establecidos. Así entonces, el sorteo encajaba muy bien dentro de las premisas de control social fijadas por las reformas borbónicas en el siglo XVIII ${ }^{8}$ por cuanto se llevaba a cabo bajo una estricta vigilancia donde no había preocupación por el desorden, la mezcla interétnica y el consumo de bebidas embriagantes que era usual hallar en algunos sitios de juegos prohibidos como el naipe y los dados?.

La participación en el juego de la lotería era amplia por cuanto personas de cualquier condición social y étnica podían acceder a una boleta. Las apuestas desmedidas,

\footnotetext{
${ }^{5}$ El bis bis era un juego muy común y consistía en una especie de ruleta en torno a la cual se fijaban las apuestas.

${ }^{6}$ Viqueira Albán, Juan Pedro. Relajados o reprimidos (México: Fondo de Cultura Económica, 1987), p. 18.

${ }^{7}$ Jiménez Meneses, Orián. El frenesí del vulgo. Fiestas, juegos y bailes en la sociedad colonial (Medellín: Universidad de Antioquia, 2007), p. 149.

${ }^{8}$ Guimerá, Agustín (ed.). El Reformismo Borbónico: una visión interdisciplinaria (Madrid: Alianza Editorial, 1996), pp. 37-59.

${ }^{9}$ Sobre esta temática: Pita Pico, Roger. "Censuras y regulaciones a los juegos de albur en el Nuevo Reino de Granada, siglo XVIII”, en Boletín de Historia y Antigüedades, vol. CI, núm. 858, Bogotá: Academia Colombiana de Historia, 2014, pp. 115-142.
} 
que era la otra gran preocupación de las autoridades, en el caso de las loterías aparentemente no tenía cabida por cuanto se establecían montos fijos en las boletas cuyo valor era asequible para amplios sectores de la sociedad. En términos fiscales, la lotería también se enmarcaba dentro de los parámetros de la política borbónica en la medida en que era un juego a través del cual el gobierno español buscó la oportunidad de contribuir a las arcas reales sin necesidad de gravar a la sociedad con más tributos.

\section{Los inicios del juego en la época colonial}

Ante la popularidad de las loterías que se realizaban clandestinamente, el gobierno neogranadino decidió establecer el monopolio a finales del siglo XVIII con propósitos fiscales y de beneficencia ${ }^{10}$. Así entonces, asumió una actitud ambivalente por cuanto, por un lado, se proscribían los juegos de azar pero, por otro, había un interés en las rentas que producían los juegos legales de lotería y naipes ${ }^{11}$.

Hacia febrero de 1782 varios oficiales Reales de la provincia de Antioquia presentaron una propuesta al virrey Manuel Antonio Flórez que buscaba aumentar las rentas estatales no a través del establecimiento de monopolios sino con el fomento a los sectores productivos. Para ello sugirieron la creación de montepíos, una especie de organismos financieros destinados a facilitar recursos a los gremios de agricultores, mineros y comerciantes de las ciudades de Santa Fe de Antioquia, Medellín y Rionegro. Uno de los fondos previstos para financiar este proyecto era el 10\% de una lotería de 100.000 patacones que se jugaría cada tres meses en todo el Nuevo Reino, cuyo manejo le sería concedido a dichos montepíos al menos mientras el Monarca se decidía a establecer este juego como un ramo de la Real hacienda. Esta lotería tenía como referencia la reglamentación vigente en España o México ${ }^{12}$.

Sin embargo, la propuesta no fue acogida. Durante el periodo de dominio hispánico únicamente dos loterías funcionaron en territorio neogranadino y se jugaron en la ciudad de Santa Fe, bajo el respaldo y acompañamiento del gobierno virreinal. Hacia el mes de junio de 1792 se estableció la primera de estas loterías públicas, cuyo desarrollo y vicisitudes pudieron observarse a través de las páginas del Papel Periódico de Santafé de Bogotá. Se sorteó mensualmente con un fondo disponible de 1.000 pesos. El $2^{\circ}$ sorteo se efectuó el domingo $1^{\circ}$ de julio y los premios entregados fueron de 875 pesos, quedando 25 pesos para los gastos de funcionamiento y 100 "con destino al objeto de este establecimiento"13. En vista de que el millar de boletas era insuficiente para satisfacer las demandas de los apostadores, se adicionaron 125 billetes para el tercer sorteo, aplicando 100 pesos al premio mayor y agregando otro premio de 25 pesos $^{14}$.

\footnotetext{
${ }^{10}$ Vargas Lesmes, Julián. Historia de Bogotá... Op. Cit., tomo IV, p. 50.

${ }^{11}$ Lozano Armendares, Teresa. "Los juegos de azar: una pasión novohispana?", en Estudios de Historia Novohispana, vol. XI, núm. 11, México: Universidad Nacional Autónoma de México, 1991, p. 176.

${ }^{12}$ Pardo, Andrés y Visadias, Francisco José. "Plan fiscal y económico para la provincia de Antioquia (1782)", en Anuario Colombiano de Historia Social y de la Cultura, núm. 9, Bogotá, Universidad Nacional de Colombia, 1979, pp. 131-142.

13 "Otra", Papel Periódico de Santafé de Bogotá, núm. 73, 6 de julio de 1792, p. 176.

14 “Nota”, Papel Periódico de Santafé de Bogotá, núm. 75, 20 de julio de 1792, p. 162.
} 
A raíz de la aceptación que había alcanzado el juego en la comunidad santafereña, el virrey José de Ezpeleta decidió aumentar los premios para el $5^{\circ}$ sorteo a celebrarse en el mes de septiembre, por lo cual se duplicó el número de boletines o billetes, es decir, se imprimieron un total de 2.000 mientras que los premios se elevaron a 1.800 pesos repartidos en 16 suertes de la siguiente manera: 1 premio mayor de 1.800 pesos, 1 de 300 pesos, 1 de 100 pesos, 4 de 50 pesos y 8 de 25 pesos. Sobresale en este sorteo la cuantiosa cifra ofrecida como premio mayor y la distancia con los otros premios que eran de baja monta.

Esta noticia fue recibida con tan buena acogida que en los primeros cuatro días de septiembre ya se había vendido la totalidad de los 2.000 números, ante lo cual el gobierno decidió adicionar 500 boletines más para el sorteo de octubre, en el cual finalmente se otorgaron 2.250 pesos a los ganadores ${ }^{15}$. Para la $6^{a}$ extracción a jugarse el $1^{\circ}$ de noviembre el gobierno adicionó 500 boletines para un total de 3.000 distribuidos en 24 suertes: 1 de 1.000 pesos, 1 de 400 pesos, 1 de 200 pesos, 5 de 100 pesos, 8 de 50 pesos y 8 de 25 pesos $^{16}$.

Al parecer, la expectativa que había generado el juego en sus primeros meses empezó a descender y hubo necesidad de reducir el número de boletas a 2.000, así como el monto de los premios. Según lo denunció con preocupación el procurador general en carta enviada el 29 de abril de 1793 al cabildo de la ciudad, para el $11^{\circ}$ sorteo a jugarse el $1^{\circ}$ de mayo se habían dejado de vender 500 boletas. Al ser enterado de esta novedad, el virrey decidió de todos modos realizar el sorteo pero tomando la prevención de cancelar los boletos sobrantes ${ }^{17}$.

El desencanto que se había suscitado en torno al juego pudo palparse al interior de una de las habituales reuniones de la Tertulia Eutropélica fundada hacía pocos meses por el editor del Papel Político de Santafé de Bogotá. Tras escuchar el lamento de algunos apostadores frustrados por no haberse llevado el premio mayor, intervino en la reunión una dama que aseguró tener la fórmula segura para ganar. Ella hizo énfasis en que siempre el sorteo beneficiaba a los más desfavorecidos económicamente, como fue el caso de una viuda con varios hijos que había aliviado con la suerte muchas de sus penurias económicas al igual que otros pobres residentes en la ciudad. Así entonces, estos afortunados ya no serían una carga para el gobierno y, por el contrario, podían ser útiles a la sociedad. Por otro lado, la referida dama recordó que estaba por todos comprobado el buen destino que se le daba al fondo resultante de cada sorteo en procura de una obra piadosa.

En tal orden de cosas y, bajo la concepción de una caridad ilustrada, ella estaba convencida de que en la lotería nadie perdía porque, en virtud de los deberes del

\footnotetext{
${ }^{15}$ AGN, Sección Colonia, Fondo Empleados Públicos-Cartas, t. II, ff. 503r-504r; "Lotería pública”, Papel Periódico de Santafé de Bogotá, núm. 80, 24 de agosto de 1792, p. 232; núm. 85, 5 de octubre de 1792, p. 256.

16 “Al público", Papel Periódico de Santafé de Bogotá, núm. 84, 21 de septiembre de 1792, p. 248.

17 “Noticia al público”, Papel Periódico de Santafé de Bogotá, núm. 89, 10 de mayo de 1793, p. 292.
} 
hombre en sociedad, era prioritario contribuir al bien común a través de la solidaridad, la cual se construía participando en este juego. Nadie podía descartar la posibilidad de acceder a la esquiva suerte a través de un medio sencillo y exento de fraudes y, por ello había que insistir hasta obtener un buen resultado. En ese sentido, se resaltó el hecho de que el método y reglamento aplicado en esta capital distaba mucho de algunas frustrantes experiencias conocidas en otras naciones, como por ejemplo la lotería implementada por los genoveses donde había que adivinar hasta cinco números para poder ganar algún premio. Es decir, se verificaban varios sorteos seguidos sin que entre la población pudiera salir un billete ganador quedando de esta manera toda la utilidad para los banqueros de aquella ciudad europea. Con estas palabras, la referida dama intentó terminar de persuadir a sus contertulios:

[...] y no sé yo, ¿qué hombre verdaderamente racional deje de complacerse de contribuir por su parte a unos fines tan propios de la Humanidad, de la Religión y del Patriotismo?

He aquí, señores, demostrada sencillamente la verdad de mi proposición, que aunque vosotros creísteis sería alguna extravagante paradoja, me parece quedareis convencidos de lo contrario: y quizá más propensos a examinar en lo sucesivo aquel fin puramente filosófico que constituye el mérito intrínseco de los objetos, y el valor esencial de las pérdidas y ganancias ${ }^{18}$.

Era esta una percepción filantrópica de la lotería quedando claro el mensaje a los acaudalados para que exteriorizaran su compromiso en favor de los más desvalidos. Ante la escasez de fuentes que revelen la opinión frente a la lotería, este episodio en particular se constituye en un indicio de las expectativas y debates suscitados en torno a este juego de azar en la Santa Fe colonial, por lo menos en los sectores letrados de la sociedad.

Pese a las intenciones de estas reflexiones, el desinterés por el juego siguió en aumento pues para el mes de octubre quedó reducido a 1.000 pesos, de los cuales 900 serían sorteados en ocho premios: 1 de 500 pesos, 1 de 100 pesos y los 6 restantes de a 50 pesos cada uno. En el caso hipotético de que no pudieran venderse las 1.000 boletas, en aras de garantizar el sostenimiento económico del juego se ordenó rebajar el premio mayor de 500 pesos en proporción directa a la merma experimentada ${ }^{19}$.

En este mismo año el cura Faustino Flórez solicitó al virrey Ezpeleta que de las utilidades del 10\% de la lotería se aplicara una parte para el establecimiento de una junta de policía. El cabildo había planteado otras alternativas para financiar esta junta, como por ejemplo gravar la miel utilizada para la fabricación de licores en la ciudad $^{20}$. Con el fin analizar y dar trámite a la propuesta, el virrey pidió se especificara

\footnotetext{
18 “Modo de no perder en la lotería", Papel Periódico de Santafé de Bogotá, núm. 90, 17 de mayo de 1793, p. 300 .

19 "Noticia", Papel Periódico de Santafé de Bogotá, núm. 110, 4 octubre de 1793, p. 460.

${ }^{20}$ Ortega Ricaurte, Enrique. Cabildos de Santafé de Bogotá, cabeza del Nuevo Reino de Granada 15381810 (Bogotá: Ministerio de Educación Nacional, 1957), pp. 198-200.
} 
qué cantidad exacta requerían y en qué serían invertidos esos auxilios ${ }^{21}$. Este primer experimento de lotería llegó a su fin aunque por las actas del cabildo se sabe que el 27 de febrero de 1798 don Juan José Barrera presentó una fianza para que se le concediera licencia para el juego de lotería ${ }^{22}$.

Muy pronto emergería un nuevo proyecto de lotería. El 16 de abril de 1801 el cabildo de la ciudad creó la denominada Lotería Municipal ${ }^{23}$. En vista de la inestabilidad experimentada en la primera lotería, en esta ocasión las autoridades se esforzaron en diseñar un reglamento muy minucioso de 30 puntos, el cual fue publicado en la prensa local para que fuera ampliamente conocido.

La lotería jugaría mensualmente con el fin de que pudieran participar no solo los vecinos de la capital ${ }^{24}$ sino de otras ciudades y lugares sufragáneos. Entrarían en juego 2.000 cédulas de valor divididas en 10 boletines para un total de 20.000 boletas a 2 reales cada una. Así entonces, el apostador podía comprar una cédula completa o elegir boletines de manera independiente y aleatoria. El vendedor debía anotar el nombre del comprador en cada boleta y en el libro de ventas, considerándose nula aquella boleta que apareciera sin estos requisitos. Este método de control y cotejo se hacía con el objeto de precaver fraudes y le permitiría además a los compradores corroborar la validez de su boleta cuando esta se le perdiera accidentalmente.

Concluido el expendio, el libro de ventas debía depositarse con el dinero recaudado en un arca de tres llaves que se mantendría en la casa del alcalde de primer voto. Las otras dos llaves estarían a cargo del regidor de turno y del secretario del ayuntamiento. Si se llegaba a detectar alguna malversación o pérdida de dineros, los tres eran responsables y asimismo debían responder con sus patrimonios y además, quedarían privados de sus cargos " [...] pues un exceso semejante infama la persona y la degrada de aquel concepto y honor que autoriza a los empleos públicos"25.

Para cada sorteo había que designar por turno un regidor que fungiría como presidente, encargado no solo de la impresión de las boletas sino también de coordinar todos los detalles del proceso sin que en ningún caso un mismo regidor organizara dos sorteos de manera sucesiva, esto con el fin de evitar cualquier suspicacia. Era potestad de ellos escoger el paraje y personal idóneo para el expendio de las boletas. Todos

\footnotetext{
${ }^{21}$ AGN, Sección Colonia, Fondo Miscelánea, t. 113, ff. 845r-847r.

${ }^{22}$ Actas de la Junta Municipal de propios de Santa Fe de Bogotá (Bogotá: Ediciones del Concejo, 1938), vol. I, p. 33.

23 "Reglamento", Correo Curioso de Santafé de Bogotá, núm. 30, 8 de septiembre de 1801, pp. 117-120; "Concluye el Reglamento", Correo Curioso de Santafé de Bogotá, núm. 31, 15 de septiembre de 1801, pp. 121-123.

${ }^{24}$ Según estadísticas publicadas por este mismo órgano periodístico, en su marco urbano la ciudad de Santa Fe contaba en este año con un total de 21.464 habitantes distribuidos en 195 manzanas. "Padrón de Santafé”, Correo Curioso de Santafé de Bogotá, núm. 6, 24 de marzo de 1801, p. 22.

25 “Concluye el Reglamento, Correo Curioso de Santafé de Bogotá, núm. 31, 15 de septiembre de 1801, p. 123.
} 
estos controles se fijaron con el propósito de que el público pudiera comprobar la escrupulosidady delicadeza con que se manejaba el sorteo, cuyas utilidades solo tenían un propósito que era una obra de beneficio público. Por ello, el regidor debía velar también porque el dinero recogido fuera legítimo, siendo él responsable de reponer cualquier moneda falsa o de desecho. Para la mecánica del sorteo, se introducían en un globo 2.000 cédulas numeradas y en un segundo globo se ingresaban igual número de papeletas de las cuales únicamente eran marcadas 16 con la frase "Esta gana pesos" que correspondían a 2 premios de 1.000 pesos, 1 de 400 pesos, 2 de 300 pesos, 3 de 200 pesos y 8 de 100 pesos.

El sorteo sería efectuado públicamente el día primero de cada mes a las nueve de la mañana en la sala del juzgado con presencia de varias autoridades y testigos. Bajo la supervisión del alcalde de primer voto y del regidor de turno, a la derecha estaría el escribano del ayuntamiento con el globo que contenía las 2.000 balotas con las cédulas numeradas y a la izquierda el escribano numerario a cargo del otro globo con las 2.000 papeletas marcadas con la palabra blanca, excepto las 16 premiadas. A continuación, se daba vueltas simultáneamente a los dos globos mientras dos niños sacaban las balotas, cuyos resultados serían puestos sobre la mesa ante los ojos del público. El escribano de cabildo anunciaba en voz alta el número de la boleta mientras que el escribano numerario revelaba si coincidía con una balota blanca o premiada. Posteriormente, se procedía a confrontar el número premiado con el registro en el cuaderno de ventas para determinar a quién o a quiénes correspondía la cuantía ganada, información que sería anotada en un pliego de papel con el sello Real en donde se pegarían con lacre las papeletas jugadas para mayor constancia y garantía de los resultados.

Una vez ejecutado el sorteo, todo estaba dispuesto para hacer directamente el pago a los ganadores asistentes. Se fijaron cuatro días de plazo para reclamar los premios o de lo contrario debían esperar hasta el próximo sorteo y, transcurrido un año, lo que no fuese reclamado sería adicionado a la obra pública patrocinada por la lotería. Los resultados serían expuestos en las puertas del cabildo para que fueran de público conocimiento. En caso remoto de quiebra o falta de dinero, se daría aviso al virrey para que adoptara los correctivos del caso.

Las 2.000 cédulas de a 20 reales cada una arrojarían un total de 5.000 pesos, de los cuales debía sacarse el $12 \%$, es decir 600 pesos, para los gastos de manejo. El restante, es decir 4.400 pesos, correspondía a los pagos de los premios. Del rubro de gastos se le asignaría al regidor de turno 100 pesos para el papel, la impresión de boletas, el proceso de expendio y el cuaderno de ventas. Entre tanto, al alcalde y al regidor se les gratificaría con 16 pesos a cada uno, 6 pesos a cada escribano y un peso con 4 reales cada uno de los dos niños colaboradores. Los 453 pesos restantes serían aplicados a una obra de beneficio público que, según el concepto previo emitido por el cabildo, la de mayor necesidad para la ciudad en ese momento era una casa de recogidas para castigo y contención de mujeres abandonadas y 
Los inicios del juego de lotería en Colombia: entre la suerte, el control social...

$\operatorname{prostitutas}^{26}$ pues "[...] la santidad y utilidad de este pensamiento no necesita de ponderarse: sus efectos son interesantes a la religión, al Estado, al beneficio público y arreglado gobierno de la capital"'27.

El 3 de agosto el virrey Pedro Mendinueta aprobó este reglamento aunque dejó por sentadas algunas observaciones. Sugirió que entre los funcionarios que debían presenciar y vigilar el sorteo asistiera también el procurador general. Los gastos de papelería e impresión no debían estimarse como un monto fijo sino que estaban supeditados a los costos de cada sorteo. El virrey dio su pleno aval al propósito filantrópico que se había propuesto la sala capitular con la creación de la casa de recogidas.

A través de la sección de avisos del Correo Curioso de Santafé de Bogotá, se informó el 15 de septiembre a los capitalinos que el despacho de la Lotería Municipal se había instalado en la tienda núm. 12 de la calle de la Carrera, en donde los apostadores interesados podían adquirir las boletas desde las nueve de la mañana hasta las doce del mediodía ${ }^{28}$. A mediados del mes siguiente la oficina fue trasladada a pocos pasos de allí a fin de asegurar mayor comodidad en el servicio ${ }^{29}$. El $1^{\circ}$ de noviembre se procedió al primer sorteo con solo ocho premios porque el estrecho margen de tiempo no dio lugar a que participaran jugadores de fuera de la ciudad y, resultado de ello, fue el hecho de que solo se vendieron 1.000 boletas de a 20 reales. Tal como lo indica el siguiente cuadro, el total de premios entregados ascendió a 2.200 pesos.

Cuadro 1. Resultados del primer sorteo de la Lotería Municipal realizado en Santa Fe el $1^{\circ}$ de noviembre. de 1801.

\begin{tabular}{|c|c|c|}
\hline No. suerte & No. ganador & Premio \\
\hline $1^{\mathrm{a}}$ suerte & 952 & 100 pesos \\
\hline $2^{\mathrm{a}}$ suerte & 288 & 100 pesos \\
\hline $3^{\mathrm{a}}$ suerte & 236 & 1.000 pesos \\
\hline $4^{\mathrm{a}}$ suerte & 593 & 100 pesos \\
\hline $5^{\mathrm{a}}$ suerte & 10 & 200 pesos \\
\hline $6^{\mathrm{a}}$ suerte & 305 & 100 pesos \\
\hline $7^{\mathrm{a}}$ suerte & 740 & 200 pesos \\
\hline $8^{\mathrm{a}}$ suerte & 644 & 400 pesos \\
\hline
\end{tabular}

Fuente: “Aviso al público”, Correo Curioso de Santafé de Bogotá, núm. 39, 10 de noviembre de 1801, p. 156.

\footnotetext{
${ }^{26}$ Este tipo de instituciones se enmarcaban dentro de las ideas de la Ilustración que abogaban por la urgencia de sustituir los criterios paternalistas de la caridad por aquellos que pregonaban la rehabilitación a través del trabajo productivo y la educación moral. Vargas Lesmes, Julián. Historia de Bogotá, t. III (Bogotá: SalvatVillegas Editores, 1989), p. 69. En ese momento, la ciudad contaba con un hospicio para hombres y otro para mujeres. "Padrón General", Correo Curioso de Santafé de Bogotá, núm. 5, 17 de marzo de 1801, p. 18.

27 “Concluye el Reglamento", Correo Curioso de Santafé de Bogotá, núm. 31, 15 de septiembre de 1801, p. 123.

${ }^{28}$ Ibid., p. 124.

29 “Noticias sueltas”, Correo Curioso de Santafé de Bogotá, núm. 35, 13 de octubre de 1801, p. 140.
} 
Hacia el año de 1802, algunas de las utilidades de la lotería se destinaron de manera extraordinaria para enfrentar una epidemia de viruela que cada vez tomaba más fuerza en la ciudad. Ante esta contingencia, el virrey Mendinueta comisionó al alcalde de segundo voto don Miguel Rivas y al mayor provincial don José Antonio de Ugarte para que adelantaran gestiones con miras a la construcción de hospitales. No obstante, las rentas de propios y los recursos provenientes de la lotería resultaban cortos para hacer frente a la emergencia sanitaria. Ante esta circunstancia, Mendinueta convocó a una junta superior de la Real Hacienda y allí se acordó recurrir al fondo de hospitales vacantes.

Fue necesario implementar nuevas medidas de prevención que al final resultaron efectivas por cuanto se logró contener la epidemia. Pese a que varios sectores reconocieron las diligentes providencias adoptadas por el virrey, el cabildo no vaciló en criticarlo por haber dispuesto de los fondos municipales y de los recursos de lotería que estaban destinados para la construcción de la galera de mujeres, obra que no pudo llevarse a cabo por escasez de recursos. El virrey se defendió de las imputaciones reiterando que había intervenido por ser un asunto de extrema urgencia y que a fin de cuentas se había recurrido a dineros oficiales para financiar una obra de beneficio público. Aprovechó además la ocasión para culpar a los cabildantes por no haber solicitado el auxilio de las rentas eclesiásticos. Al final, el Rey absolvió a Mendinueta de toda culpa ${ }^{30}$.

\section{La lotería durante el proceso de Independencia}

Los progresos conseguidos en el manejo administrativo y operativo del juego de la lotería sufrirían un serio retroceso en el periodo de Independencia que se inició con las primeras manifestaciones de emancipación política en julio de 1810. El estado de devastación, que produjo no solo el enfrentamiento político y militar entre patriotas y españoles sino también el conflicto interno entre centralistas y federalistas, sumado al estancamiento de la economía y la inseguridad social reinante ${ }^{31}$, eran factores que generaron desinterés hacia la lotería por ser precisamente este un juego basado en la apuesta de dinero. El ambiente de guerra, caracterizado por los continuos saqueos, embargos, contribuciones forzosas y destierros, produjo una situación de iliquidez y desestímulo para las apuestas. De igual modo, el gobierno que había sido desde tiempos coloniales el organizador oficial del juego, se hallaba ahora abrumado con múltiples ocupaciones asociadas al reto de sostener la guerra.

Este cúmulo de circunstancias permite comprender por qué durante esta fase de Independencia solo funcionó una lotería, cuya existencia fue muy fugaz precisamente por la atmósfera de inestabilidad y agitación política. Este único experimento fue la denominada Lotería Popular de Cundinamarca establecida en la ciudad de Santa

\footnotetext{
${ }^{30}$ Groot, José Manuel. Historia Eclesiástica y Civil de Nueva Granada, t. II (Bogotá: Imprenta a cargo de Foción Montilla, 1869), pp. 102-103.

${ }^{31}$ Castillo y Rada, Rafael del. Memorias que el Secretario de Estado y del Despacho de hacienda presenta al Congreso de Colombia sobre los negocios de su Departamento (Bogotá: Imprenta del Estado, por Nicomedes Lora, 1823), p.1.
} 
Fe en agosto de 1811 bajo el mandato republicano del presidente del Estado de las Provincias Unidas don Antonio Nariño. En esta ocasión se pusieron en venta los billetes y boletines, programándose el primer sorteo para el siguiente mes. Finalmente este juego no se llevó a cabo en la fecha propuesta por falta de tiempo en el proceso de organización y solo pudo realizarse hasta el 16 de febrero del año siguiente. En total, se entregaron 500 pesos repartidos en 9 premios de 10, 12, 50100 y 250 pesos $^{32}$. Se hace evidente cómo el monto de premios ofrecidos estaba muy por debajo de lo registrado en los sorteos organizados en esta misma ciudad a finales del siglo XVIII y primeros años del siglo XIX.

En 1812 las Cortes de Cádiz autorizaron al gobierno de la Regencia extender el establecimiento de la lotería a todos sus dominios ${ }^{33}$. En los cuatro años de la fase de Reconquista (1815-1819) en que los españoles estuvieron al frente del poder en territorio neogranadino, no se estableció ninguna lotería pero sí hubo intentos en otras latitudes del dominio hispánico. En Nueva España, por ejemplo, los gobernantes españoles crearon una lotería forzosa con el fin de recoger fondos extraordinarios para combatir la revolución ${ }^{34}$.

Debido a la escasez económica padecida por la comunidad de la Orden de Predicadores de la ciudad de Panamá, uno de sus representantes, fray Juan Pedrero, solicitó a principios de 1812 al virrey Benito Pérez un privilegio exclusivo para establecer el juego de las suertes o lotería por espacio de diez años con el compromiso de reservar la cuarta parte para la reedificación del templo de esta comunidad. Pedrero colocó como ejemplo la ciudad de Lima donde se había creado una lotería a beneficio de la reconstrucción de la iglesia parroquial de San Marcelo y, al concluirse estos trabajos, se abrió paso a una obra pía que con el tiempo había brindado resultados bastante favorables.

Sobre esta solicitud el gobierno virreinal dictaminó que, además del proyecto de reedificación, había que plantear una obra de beneficio público para atender las múltiples necesidades que padecía la ciudad, como por ejemplo la construcción del acueducto, la reparación del hospital de pobres, la construcción de un cementerio, el alumbrado público o la edificación de un hospicio. En ese sentido, se exigieron cuentas precisas sobre los costos que acarrearía el proceso de reconstrucción del templo para ajustar las cifras de los premios que se ofrecerían en el sorteo ${ }^{35}$.

Aunque en la ciudad de Lima ya existía un sorteo semanal, la Corona tomó la decisión de crear oficialmente el ramo de loterías. Así entonces, don Gaspar Rico y Angulo, ministro honorario de la Real Hacienda en el Perú, logró en noviembre de 1817 con el aval del Rey establecer una lotería oficial con la cual quedaba abolida cualquier otro juego similar manejado por particulares. Este asentista reiteró a los ayuntamientos, a los tribunales de consulado y a los gremios el llamado que había hecho el Monarca para que se interesaran

\footnotetext{
32 “Aviso", Gazeta Ministerial de Cundinamarca, núm. 30, 20 de febrero de 1812, p. 112.

${ }^{33}$ Lucena Giraldo, Manuel, Op. Cit., p. 266.

${ }^{34}$ Cordoncillo, José María, Op. Cit., p. 264.

${ }^{35}$ AGN, Sección Archivo Anexo, Fondo Eclesiásticos, t. 24, f. 121r.
} 
por el fomento de las loterías, teniendo siempre como meta la utilidad común. Las dos terceras partes de lo recogido en cada sorteo serían destinadas al plan de premios y el restante sería reservado para una obra de beneficio social. Rico y Angulo pidió que lo respaldaran en su proyecto pues la idea era que cada individuo pudiera invertir

[...] pequeñas cantidades de dinero o valores mínimos, que nada produce al que los gasta, al que los conserva, ni al que los invierte buscando alguna ganancia. De este centro han de salir cantidades mayores, capaces de dar sustento y fomento a muchas familias por medio de una suerte adquirida sin costo, sin riesgo y sin delito $[\ldots]$ se alimentarán muchos, se contraerán algunos matrimonios, se cumplirán los deseos o votos religiosos de varias personas sacrificadas por no tener, no poder, ni saber adquirir un dote que perpetúe su subsistencia; y pasará un bien de una a otras generaciones ${ }^{36}$.

Así entonces, se concebía a la lotería como una oportunidad de asegurar a los padres de familia una alternativa de bienestar económico a largo plazo que les permitiese alimentar y educar a sus hijos. El objetivo era establecer el plan piloto de lotería en la ciudad de Lima y luego, con el paso del tiempo y con la experiencia adquirida, Rico y Angulo se convirtiera en el director de un plan más ambicioso: la Real Lotería de la América Meridional ${ }^{37}$, cuya sede general sería Lima o cualquier otra ciudad de la región. Con miras a dar cumplimiento a este proyecto, se hizo énfasis en que había que ofrecer las facilidades y orientaciones necesarias al virrey de Santa Fe y a los gobernadores de Chile, Río de la Plata, Caracas, Quito, Charcas y Cuzco.

El texto de este decreto Real fue reproducido en 1819 en las ciudades de Santa Fe y Medellín pero no existen pruebas de haberse avanzado en la concreción de esta propuesta pues por estos días el virrey Juan Sámano estaba en máxima alerta ante la inminente llegada del Ejército Libertador que finalmente lograría imponerse, permitiéndole a los republicanos recuperar definitivamente el $\operatorname{poder}^{38}$. Tal como lo informó la Gaceta de Cartagena de Colombia ${ }^{39}$, hacia el año de 1822 el agónico gobierno español intentó sin mucho éxito restablecer esta lotería en Perú pero poco tiempo después este territorio sería también conquistado por los republicanos.

\section{Nuevos impulsos en la naciente República}

En agosto de 1819, tras el triunfo alcanzado en la Batalla de Boyacá, el naciente gobierno republicano emprendió en firme su independencia definitiva, teniendo

\footnotetext{
${ }^{36}$ AGN, Sección Archivo Anexo, Fondo Historia, t. 25, f. 440r.

${ }^{37}$ Existe un antecedente de estas intenciones por manejar el ramo en buena parte del territorio novohispano. Se trata de la solicitud que a finales del siglo XVIII elevó don Francisco Xavier Sarría, director de la renta de lotería en Nueva España, quien propuso sin mucho éxito al Rey tomar en arrendamiento la renta con el propósito de extenderla a toda América. Cordoncillo, José María, Op. Cit., p. 239.

${ }^{38}$ AGN, Sección Archivo Anexo, Fondo Reales Cédulas y Órdenes, t. 42, ff. 61r-63r; Archivo Histórico de Medellín (AHM), Fondo Concejo de Medellín, t. 91, ff. 267-268v. En Caracas también fue difundida la mencionada cédula real pero tampoco hay indicios de haberse aplicado. "Lotería", Gaceta de Caracas, núm. 248, 19 de mayo de 1819, pp. 1911-1912.
}

${ }^{39}$ AGN, Sección República, Fondo Peticiones-Solicitudes, t. 3, f. 307r. 
como meta liderar el proceso de recuperación económica y sentar las bases de una nueva estructura administrativa y burocrática. Durante estos años iniciales de vida republicana, se mantuvo el manejo oficial del juego de lotería y asimismo el Estado retomó la política asumida por las autoridades españolas en tiempos del dominio hispánico de controlar los juegos de azar y evitar que estos se convirtieran en focos de desorden social o detrimento económico para los ciudadanos.

El juego de lotería logra afianzarse con una mayor regularización y descentralización de los sorteos, registrándose además un aumento en los fondos y premios. Hacia 1823 el gobierno central decidió entregar el monopolio de la lotería a los departamentos, quienes debían destinar la ganancia a la beneficencia social ${ }^{40}$.

Se estableció la lotería en cuatro ciudades principales: Bogotá, Medellín, Cartagena y Mompós. En medio de la crisis fiscal imperante, el propósito principal al impulsar estos juegos era obtener utilidades que serían invertidas en obras de beneficio público, una alternativa de alivio ante la escasez de las arcas estatales ${ }^{41}$.

Fue claro el interés del gobierno central en apoyar y respaldar las iniciativas surgidas a nivel local y provincial. En Bogotá la iniciativa surgió en una reunión de la Junta Municipal de Propios efectuada el 28 de septiembre de 1819, en la cual el procurador general habló de la conveniencia de restablecer la lotería, pues traería gran utilidad al público y su producto sería destinado al mejoramiento de las rentas municipales. La Junta decidió unánimemente transmitir esta propuesta al cabildo ${ }^{42}$. La idea fue aprobada por las autoridades locales y avaladas por el gobierno nacional. Es así como el 16 de marzo de 1820 el vicepresidente Francisco de Paula Santander expidió un decreto mediante el cual declaraba formalmente la lotería en Bogotá. La decisión se tomó en vista del estado deficitario de la renta de propios de la ciudad, razón por la cual los caminos se hallaban descompuestos, los puentes y calzadas amenazaban ruina, siendo evidente además el estado de abandono de los asuntos de policía. Así entonces, con el fin de aumentar los productos de la renta municipal y tener cómo asumir las funciones de gobierno sin gravar al pueblo, se optó por crear una lotería pública que jugaría el primer miércoles de cada mes.

Por lo pronto, el fondo sería de 2.000 pesos y se emitirían igual número de boletas, cada una a un peso. Estas boletas serían vendidas por el escribano de la junta municipal en el juzgado ordinario bajo la presencia del alcalde de primer voto, y debían ser

\footnotetext{
${ }^{40}$ Alonso Cifuentes, Julio César y Gallego Londoño, Ana Isabel. "Concesión del monopolio de juegos de apuestas y azar en el Valle del Cauca”, en Estudios Gerenciales, vol. XXVI, núm. 116, Cali, ICESI, 2010, p. 214.

${ }^{41}$ El desequilibrio fiscal registrado en estos primeros años del periodo republicano fueron más que evidentes a lo cual se le sumaban los problemas en el recaudo de impuestos y los continuos fraudes y evasiones. El monto general de gastos de la naciente República sobrepasaba fácilmente los ingresos. Para el año de 1823, por ejemplo, los ingresos fueron estimados en 5 millones de pesos en tanto que las exigencias fiscales casi triplicaban esa cifra. Bushnell, David. El Régimen de Santander en la Gran Colombia (Bogotá: El Áncora Editores, 1985), p. 123.

${ }^{42}$ Actas de la Junta... Op. Cit., vol. II, pp. 253-254.
} 
impresas y rubricadas por los integrantes de la junta de propios, quedando en un libro la constancia del nombre del comprador y del número apostado. Los dineros recaudados serían depositados en un arca de tres llaves que estarían en manos del alcalde, del procurador general y del regidor miembro de la junta municipal. La lotería tendría 13 suertes o premios: 1 de 500 pesos, 1 de 300 pesos, 2 de 200 pesos, 3 de 100 pesos y 6 de 50 pesos. En una mesa debía ubicarse el arca con el dinero y dos urnas o globos, una con las cédulas de los números y la otra con papeletas premiadas y otras en blanco en igual número que aquellas.

Se hizo énfasis en que el sorteo no sería aplazado a pesar de que no fueren vendidas la totalidad de las boletas. Sin embargo, previo aviso al público el día anterior, los premios disminuirían en valor a proporción del número de boletas no vendidas. Una vez repartidas las cantidades premiadas, y deducidos los costos, la suma restante iría al arca de la junta de propios. El reglamento no contempló más gastos que aquellos necesarios para la impresión de las boletas y el pago de 6 pesos al escribano y un peso a cada niño encargado de extraer las boletas, gastos que en su primera vez serían asumidos por la renta de propios y en las sucesivas ocasiones por las utilidades obtenidas $^{43}$. Al igual que el modelo instaurado en 1801, es claro observar cómo esta lotería estipuló mecanismos de control para evitar cualquier fraude y se fijaron ajustes en el monto del premio con el fin de asegurar la estabilidad económica del negocio.

Difundido el reglamento, el 27 de junio el cabildo destinó 100 pesos para los gastos que acarrearía la implementación del juego ${ }^{44}$. A principios del mes siguiente, en la escribanía $1^{\mathrm{a}}$ numeraria, se colocaron en venta las boletas que en tan solo unos días lograron venderse en su totalidad ${ }^{45}$. A mediados de marzo de 1821 se anunció que en adelante el sitio de expendio sería la tienda del ciudadano Rafael Flórez en la calle del Comercio $^{46}$. Durante las fiestas nacionales ${ }^{47}$ realizadas en esta capital a finales de diciembre de 1823 se programó un sorteo extraordinario, esta vez a favor de diez mendigos con un fondo proporcionado por el ayuntamiento mientras que al resto de pobres se les brindó un pequeño auxilio económico ${ }^{48}$.

En la provincia de Antioquia la idea de instaurar el juego de lotería provino de parte de la Sociedad de Amigos del País de la villa de Medellín. En consideración a la falta de recursos para obras públicas como composición de caminos, puentes, aseo y ornato, esta Sociedad propuso el 20 de junio de 1822 la creación de una lotería pública, de la cual se pudiera destinar el diez por ciento del producto de las boletas para cubrir aquellas obras.

\footnotetext{
${ }^{43}$ López Domínguez, Luis Horacio (comp.). De Boyacá a Cúcuta. Memoria Administrativa, 1819-1821 (Bogotá: Biblioteca de la Presidencia de la República, 1990), pp.

${ }^{44}$ Actas de la Junta... Op. Cit., vol. II, p. 277.

45 "Otro", Gazeta de la ciudad de Bogotá, núm. 50, 9 de julio 9 1820, p. 194.

46 “Aviso al público", Gazeta de la ciudad de Bogotá, núm. 86, 18 de marzo 18 1821, p. 268; Actas de la Junta... Op. Cit., vol. III, pp. 192-194.

${ }^{47}$ Mediante ley se determinó que a finales de cada año habría perpetuamente una fiesta nacional consagrada a la Independencia y al establecimiento de la República y de la Constitución nacional. "Ley", Gaceta de Colombia, núm. 1, jueves 6 de septiembre de 1821, p. 4.

48 "Fiestas Nacionales", Gaceta de Colombia, núm. 116, 4 de enero de 1824, p. 1.
} 
Dentro del reglamento de 18 puntos se estipuló que el sorteo se haría el segundo domingo de cada mes y el precio de las boletas sería de 4 reales cada una. La novedad de este manual es que diseñó una extensa red de puntos oficiales de venta a nivel local. El expendio en Medellín estaría a cargo de tres comisionados, los cuales a su vez podían nombrar delegados en todos los pueblos de la provincia. Las boletas debían ser impresas y rubricadas por los tres comisionados y debía llevarse un libro en el que quedara constancia de los compradores y de los números adquiridos.

El viernes anterior al sorteo la comisión debía tener recolectado el producto de las ventas en toda la provincia y con esta información se procedería a realizar la cuenta general del sorteo. El sábado por medio de un cartel había que informar al público la cantidad recogida y los números apostados. Al igual que en Bogotá, esta lotería estableció un sistema que garantizaba los fondos de manera estable. Tendría 13 premios, uno correspondiente a la cuarta parte del total recogido, otro de la quinta parte, dos de la sexta parte, tres de la octava parte y seis de la décima parte, quedando el resto en favor del establecimiento del juego. Deducidos los gastos, las utilidades serían invertidas en la obra pública o servicio social propuesto.

A los cinco días, el gobernador Francisco Urdaneta aprobó este reglamento y nombró como comisionados a Juan Santamaría, Juan Carrasquilla y Francisco López. Para presidir el acto de sorteo en calidad de delegado del gobierno se designó al jefe político del cantón mientras que en representación del cabildo asistiría el alcalde ordinario de primer voto y el síndico procurador general, y en representación de la Sociedad estarían Manuel Tirado y José María Uribe.

La obra de beneficio público escogida por Urdaneta fue la composición de caminos $^{49}$, la cual se enmarcaba dentro del proyecto trazado por los gobernantes de esta provincia para mejorar la infraestructura de comunicaciones con el fin de constituirse en impulso al desarrollo económico y comercial. A través de la prensa el gobierno ya había convocado a los ciudadanos a que realizaran aportes voluntarios para la red de caminos de la provincia.

De acuerdo a lo estipulado en el reglamento, a través de un aviso publicado en El Eco de Antioquia se informó a la ciudadanía sobre la realización del primer sorteo para el domingo 11 de agosto pero debido a algunas demoras solo pudo concretarse el miércoles $14^{50}$. En este sorteo la señora María Ospina resultó ganadora de un premio de 15 pesos pero no habiendo ella ocurrido a reclamar su dinero e ignorándose su lugar de vecindad, fue necesario ubicarla a través de un anuncio clasificado de prensa: “[...] se avisa al público para que el que la conozca le dé la noticia y que con la boleta que acredite ser la misma u otra justificación bastante, se presente al Sr. Juez público de ella a percibir su haber" ${ }^{51}$. Para el sorteo del 27 de octubre se advirtió que ni el día de la víspera ni el día del sorteo se venderían boletas pues con bastante anticipación

\footnotetext{
49 "Sociedad de Medellín”, El Eco de Antioquia, núm. 9, 30 de junio de 1822, pp. 33-34.

50 “Otro", El Eco de Antioquia, núm. 13, 28 de julio de 1822, p. 56.

51 “Aviso al público”, El Eco de Antioquia, núm. 17, 8 de septiembre de 1822, p. 72.
} 
los apostadores podían adquirirlas en las casas de los comisionados. Esta aclaración estaba dirigida a algunos ciudadanos que en los pasados sorteos se acercaban a última hora a hacer sus apuestas ${ }^{52}$.

Cartagena fue la tercera ciudad en contar con el juego de lotería en esta segunda fase republicana. A diferencia de Bogotá y Medellín, este puerto marítimo había sentido con mayor intensidad los rigores de la guerra pues solo pudo liberarse del dominio español en noviembre de 1821 tras superar un prolongado sitio. Como era apenas de esperarse, allí el estado de devastación social y económica fue de considerable magnitud ${ }^{53}$.

Debido a la insuficiencia de recursos en la renta de propios y al estado de crisis económica que impedía costear escuelas primarias y adelantar otras obras de beneficio público en el departamento del Magdalena, el Intendente decidió mediante decreto impreso expedido el 26 de agosto de 1822 crear el juego de lotería por medio del cual cada ciudadano podía contribuir voluntariamente a proporción de sus facultades económicas y con el incentivo constante de buenos premios.

Creía el intendente que este juego, adoptado ya por otros gobiernos provinciales, era "[...] justamente el que más se necesita en estos pueblos donde la guerra ha hecho desaparecer todas las fortunas, para crear capitalistas que puedan dar más impulso a su industria y aumentar la riqueza nacional y las rentas del Estado" 54 . Los fondos oficiales de la ciudad de Cartagena resultaban insuficientes para suplir las necesidades de otras localidades pues eran recursos recolectados a partir de pequeños impuestos a productos básicos como la carne y el casabe que es el pan de los pobres.

En todo el departamento no existían peajes ni pontazgos ni otro tipo de impuestos municipales que eran comunes en otras partes y la intención del intendente era evitar gravámenes sobre las mercaderías extranjeras o sobre otras actividades productivas, pues ese tipo de medidas iban en contravía de las directrices del gobierno nacional que abogaban por incrementar la prosperidad de los pueblos. Las contribuciones voluntarias, aunque eran menos gravosas, de todas maneras resultaban muy exiguas y de muy costosa y compleja recolección. El propósito era que, una vez entrara en funcionamiento la lotería, cesaran todos los impuestos municipales aplicados al ganado y a las actividades económicas.

Se programaron dos tipos de sorteos: ordinarios y extraordinarios. Los primeros debían realizarse del 3 al 8 de cada mes a partir de noviembre y se entregarían 15.000 pesos repartidos en 410 premios así: 1 de 4.000 pesos, 1 de 2.000 pesos, 1 de 1.000 pesos, 1 de 500 pesos, 6 de 200 pesos, 10 de 100 pesos, 20 de 50 pesos, 40 de 25 pesos y 330 de 10 pesos. Era este el plan de premios más grande nunca antes visto en territorio colombiano.

\footnotetext{
52 “Aviso al público", El Eco de Antioquia, núm. 23, 20 de octubre de 1822, p. 96.

${ }^{53}$ Meisel Roca, Adolfo, "La crisis fiscal de Cartagena en la era de la Independencia, 1808-1821", en Calvo Stevenson, Haroldo y Meisel Roca, Adolfo (eds.). Cartagena de Indias en la Independencia (Cartagena: Banco de la República, 2011), pp. 371-403.

${ }^{54}$ AGN, Sección República, Fondo Ministerio de Instrucción Pública, t. 109, f. 645r.
} 
Los sorteos extraordinarios debían anunciarse con 60 días de anticipación y se jugarían cada seis meses, del 23 al 28 de abril y octubre, con el doble de premios. El valor de las acciones o boletas para uno y otro sorteo sería de 2 y 4 reales, respectivamente.

La idea era recoger cada mes bajo esta fórmula 12.000 pesos en la provincia de Cartagena, 5.000 en la de Santa Marta y 3.000 en la de Riohacha y, cada seis meses, se aspiraba a recaudar el doble de esa cantidad para organizar un sorteo extraordinario. De lo recolectado, se deduciría la cuarta parte a la cual se le rebajarían los gastos de operación y el resto sería distribuido equitativamente a favor de las tres ciudades cabeza de provincia.

Los jueces políticos y los subalternos que se nombraran en las parroquias eran los encargados del expendio de las boletas, para lo cual debían enviar a Cartagena la suma recolectada y los billetes sobrantes que serían entregados al administrador de este ramo. Tres días antes del sorteo se debía dar este reporte de cuentas y los caudales obtenidos se ubicarían en una caja de tres llaves en manos del alcalde de primer voto, del administrador y del regidor decano, quienes eran responsables de cualquier eventual pérdida.

Con el fin de imprimirle más solemnidad, dos horas antes uno de los cuerpos militares de la plaza de Cartagena anunciaba con música la realización del sorteo, el cual debía realizarse en un lugar especialmente acondicionado en el palacio de la intendencia bajo la presencia de la máxima autoridad departamental. Allí se colocarían dos globos, uno con 80.000 números de acciones o boletas y el otro con igual número de papeletas, de los cuales 410 estarían premiados y el resto en blanco. El alcalde y el regidor escogerían entre los concurrentes a dos hombres que hicieran girar los globos y dos niños sacarían las bellotas de cada globo, cuyos resultados serían anunciados por voz de pregonero. Acto seguido, los resultados eran divulgados en la plaza y demás lugares públicos de la ciudad de Cartagena, así como en las demás poblaciones del departamento. Los premiados solo podían reclamar el dinero a los tres días del sorteo. Si pasados cuatro años no aparecía el ganador, estos recursos pasarían al fondo.

Para afinar los detalles y la mecánica del juego, la intendencia procedió a expedir un completo reglamento en el cual se dispuso que la oficina de loterías funcionara con un administrador tesorero, un contador interventor y un oficial de libros. Como administrador fue nombrado Manuel Iriarte y como contador Juan Guillermo Ros. En ese manual se fijó el pago a estos empleados, así como el método de llevar las cuentas, la forma de las boletas y la distribución de estas en las poblaciones.

A fin de cuentas, se pudo agilizar el proceso de organización y se adelantó la fecha del primer sorteo para el 23 de septiembre aunque a última hora se decidió reducir el plan de premios. En la prensa se anunció que en uno de los entresuelos de la antigua casa de la Inquisición, se ofrecían billetes de este juego de azar. A través del mencionado reglamento interno, la Intendencia prometió todas las garantías necesarias pues se reconfirmó la disponibilidad de los fondos para distribuir entre los ganadores ${ }^{55}$.

55 “Aviso", Gaceta de Cartagena de Colombia, núm. 32, 21 de septiembre de 1822, p. 138. 
Pese a todas estas medidas y precauciones, no dejaron de presentarse obstáculos en la realización de este juego de azar. Así por ejemplo, a través de la prensa se informó el 4 de noviembre que el sorteo programado no podía verificarse por falta de coordinación al no tenerse razón de todos los billetes vendidos en los cantones de Santa Marta, Plato, Valledupar, Barranquilla y Corozal ${ }^{56}$. Otro de los impases fue el ambiente de guerra que todavía se vivía en algunas partes del departamento del Magdalena por cuenta de algunas facciones españolas que lanzaban sus últimos coletazos contra el régimen republicano ya constituido. Esta fue la causa por la cual a principios de mayo de 1823 se suspendió temporalmente el sorteo ante lo cual hubo necesidad de impartir instrucciones a los jueces políticos para que recogieran las boletas repartidas y devolvieran el dinero a los apostadores ${ }^{57}$.

Los cartageneros volvieron nuevamente a contar con la oportunidad de jugar lotería el domingo 28 de noviembre de 1824, noticia que fue difundida a través de la prensa local. Esta vez, los premios se pagarían en la calle de las Carretas en la casa del regidor Tomás Gordon ${ }^{58}$. Se pusieron en venta 4.000 boletas con un total de 16 premios que oscilaban entre 10 y 100 pesos. Para el sorteo realizado a finales de diciembre se entregaron 780 pesos por los 30 premios ganadores.

Los primeros sorteos de 1825 fueron realizados en la casa de los regidores comisionados Francisco Pacheco y Manuel María Guerrero. Para el sorteo del 27 de febrero las boletas no alcanzaron a producirse en la imprenta debido a la gran cantidad de trabajos pendientes, motivo por el cual fueron elaboradas manualmente ${ }^{59}$. El cuadro que aparece a continuación contiene los resultados de los sorteos desarrollados en el primer semestre de este año, observándose solo sutiles oscilaciones en el monto total de los premios entregados.

Cuadro 2. Resultados de los sorteos de la lotería de Cartagena, febrero-mayo de 1825.

\begin{tabular}{|l|c|c|}
\hline \multicolumn{1}{|c|}{ No. sorteo } & No. premios & Premios entregados \\
\hline $4^{\text {o }}$ sorteo del 27 de febrero de 1825 & 32 & 730 pesos \\
\hline $5^{\text {o }}$ sorteo del 25 de marzo de 1825 & 32 & 800 pesos \\
\hline $6^{\text {o }}$ sorteo del 24 de abril de 1825 & 32 & 780 pesos \\
\hline $7^{\circ}$ sorteo del 29 de mayo de 1825 & 32 & 800 pesos \\
\hline
\end{tabular}

Fuentes: Gaceta de Cartagena de Colombia, núm. 192, pp. 195 y 200.

Para mediados de año, más exactamente el 24 de junio, se programó un sorteo extraordinario, en el cual se introdujo por primera vez en Colombia la modalidad de premios con aproximaciones, es decir la posibilidad de recibir pequeños premios por tener un número cercano a uno de los ganadores, con lo cual se ampliaban las posibilidades de triunfo para el apostador. Para esta ocasión se imprimieron 8.000

\footnotetext{
56 “Aviso", Gaceta de Cartagena de Colombia, núm. 39, 9 de noviembre de 1822, p. 166.

57 “Aviso", Gaceta de Cartagena de Colombia, núm. 77, $1^{\circ}$ mayo de 1823, p. 326.

58 “Aviso", Gaceta de Cartagena de Colombia, núm. 172, 27 de noviembre de 1824, p. 4.

59 “Aviso”, Gaceta de Cartagena de Colombia, núm. 181, 29 de enero de 1825, p. 4.
} 
boletas a 4 reales cada una, lo cual arrojaba un total en ventas de 4.000 pesos, de los cuales 400 iban dirigidos a los fondos del juego. Se programaron 50 premios de la siguiente manera: un premio mayor de 1.000 pesos con 2 aproximaciones de 50 pesos cada una, el segundo premio mayor de 500 pesos con 2 aproximaciones de 40 pesos cada una, 2 premios de 200 pesos, 3 de 100 pesos, 2 de 80 pesos, 2 de 60 pesos, 8 de 50 pesos y 27 de 20 pesos $^{60}$. El premio mayor correspondió al número 3976 y el segundo premio mayor al 6221. En total fueron entregados 3.600 pesos en premios $^{61}$.

Al parecer, estos últimos sorteos, en especial el de carácter extraordinario, trajeron favorables resultados, pues la Intendencia decidió elevar el monto de los premios tras haberse experimentado una buena acogida no solo por parte de los cartageneros sino también de otros pueblos de la provincia. Igualmente se subrayó el hecho de que había mejorado la suerte de varios ciudadanos, quienes habían salido de su estado de pobreza. Así entonces, en adelante se jugarían las mismas 4.000 boletas que se imprimían para los sorteos ordinarios, pero se aumentó el monto de los premios de esta manera: 1 premio mayor de 500 pesos con 2 aproximaciones de 20 pesos cada una, 1 de 250 pesos con 2 aproximaciones de 20 pesos cada una, 1 de 100 pesos, 2 de 50 pesos, 2 de 40 pesos, 10 de 25 pesos y 24 de 10 pesos. La idea era recoger en ventas un total de 2.000 pesos, de los cuales 400 se reservarían para el fondo y las utilidades serían utilizadas en el aseo de la ciudad y en otra obra de servicio al público ${ }^{62}$.

Además de la lotería que funcionaba en Cartagena, también se alcanzó a establecer este juego el último domingo de cada mes en la villa de Mompós en donde asimismo se puso en práctica la modalidad de las aproximaciones. El siguiente cuadro resume los resultados obtenidos en los sorteos efectuados en esta localidad:

Cuadro 3. Resultados de los sorteos de la Lotería Municipal de Mompós jugados entre el 25 de diciembre de 1823 y el 26 de septiembre de 1824 .

\begin{tabular}{|l|l|l|}
\hline Sorteo & Total premios & Total aproximaciones \\
\hline Sorteo extraordinario del 25 de diciembre de 1823 & 166 pesos & 60 pesos \\
\hline Sorteo ordinario del 29 de febrero de 1824 & 102 pesos & 32 pesos \\
\hline Sorteo ordinario del 25 de abril de 1824 & 83 pesos & 28 pesos \\
\hline Sorteo ordinario del 30 de mayo de 1824 & 101 pesos & 30 pesos \\
\hline Sorteo ordinario del 27 de junio de 1824 & 203 pesos & 60 pesos \\
\hline $16^{\circ}$ sorteo ordinario del 26 de septiembre de 1824 & 120 pesos & 32 pesos \\
\hline
\end{tabular}

Fuente: Gaceta de Cartagena de Colombia, núms. 125, 135, 142, 149, 153, 167, años 1823-1824.

En esta lotería los premios eran mucho menores a lo ofrecido en las ciudades de Bogotá, Medellín y Cartagena pues el premio mayor no superaba los 100 pesos, razón por la cual resultaba asequible para los sectores populares.

\footnotetext{
60 "Aviso", Gaceta de Cartagena de Colombia, núm. 193, 23 de abril de 1825, p. 4.

${ }^{61}$ Gaceta de Cartagena de Colombia, núm. 203, 2 de julio de 1825, p. 4.

62 “Aviso", Gaceta de Cartagena de Colombia, núm. 204, 9 de julio de 1825, p. 4.
} 
En octubre de 1824, Isaac Poole presentó al secretario de Hacienda don José María del Castillo un proyecto para ser agente del gobierno en el manejo del juego de loterías en Colombia. Al no recibir respuesta, al cabo de un año este hombre insistió de nuevo en su idea haciéndole ver al gobierno que no necesitaría invertir previamente sino que por el contrario, contaría con un capital fijo de 30.000 pesos para realizar el sorteo. Poole puso de relieve su amplia experiencia y conocimientos en este tipo de juegos de suerte y prometió resultados positivos tanto para el gobierno como para el público. Como punto de referencia trajo a colación las loterías en Europa, en especial la de Inglaterra que llevaba más de un siglo de funcionamiento contribuyendo con una utilidad anual de 900.000 pesos. Al final, el gobierno rechazó esta propuesta ${ }^{63}$.

\section{A modo de conclusión}

Los inicios del juego de lotería en Colombia estuvieron marcados por cierta intermitencia debido a los efectos generados por la agitación política y militar ligada al periodo de Independencia. De algún modo, los cambios de gobierno generaron continuas variaciones en las reglas de juego.

En términos generales, uno de los aspectos comunes observados tanto en tiempos del antiguo régimen español como también bajo el sistema republicano, es que la lotería estuvo siempre a cargo de instancias oficiales, lo cual hizo que el estamento eclesiástico y el sector privado tuvieran muy poca participación en este negocio a pesar de que se plantearon algunas propuestas de manejo. Aunque no se estableció un único juego de lotería para todo el territorio nacional, el gobierno central cumplió una importante función de control y respaldo a las iniciativas locales.

Las seis loterías que alcanzaron a establecerse en estos años se realizaron en las principales ciudades aunque cabe precisar que su alcance real se extendía al marco provincial pues se daba el margen de tiempo para que habitantes de otras poblaciones pudiesen participar del juego. Para ello la prensa, cuyos orígenes fueron casi a la par con el desarrollo de la lotería, cumplió un papel importante pues permitía mantener informada a la comunidad sobre las fechas de los sorteos y los resultados de los mismos.

En el paso de periodo colonial al republicano no se registraron modificaciones sustanciales en la mecánica y procedimiento del juego ni tampoco en la solemnidad con que se realizaban los sorteos aunque lo que sí se observa en los inicios de vida republicana es un incremento en los controles y en el diseño de estrategias que permitieran la sostenibilidad del negocio. En los seis proyectos de lotería revisados en este artículo, el precio de las boletas se mantuvo prácticamente constante y casi siempre asequible a los sectores populares. No se registró aquí la problemática vivida con la lotería de Nueva España en 1770 cuando hubo necesidad de bajar el valor del billete de 20 a 4 pesos, planteándose como alternativa para los más adinerados una lotería especial con boletas de 100 pesos $^{64}$.

\footnotetext{
${ }^{63}$ AGN, Sección República, Fondo Peticiones y Solicitudes, t. 14, p. 772r.

${ }^{64}$ Cordoncillo, José María, Op. Cit., pp. 214-215.
} 
Durante los años finales del siglo XVIII y principios del siglo XIX se mantuvieron presentes tres objetivos claves de la lotería: el control a los juegos ilegales, la posibilidad de contar con un ingreso adicional para las rentas oficiales y la oportunidad que tenía cualquier individuo de salir de su estado de pobreza a través del juego. Aunque el propósito tanto del gobierno monárquico como del gobierno republicano era incentivar la lotería para moderar otro tipo de juegos prohibidos, a fin de cuentas lo que sucedió en realidad es que, pese a las restricciones, siguieron registrándose juegos de azar ilegales con apuestas elevadas ${ }^{65}$.

En resumidas cuentas, la mayoría de loterías no cumplieron con el propósito filantrópico que habían propuesto inicialmente con miras a apoyar los hospicios y otros lugares para socorrer a los más desvalidos de la sociedad ${ }^{66}$. Esto se explica por la necesidad imperiosa de destinar las utilidades para cubrir las esquilmadas arcas estatales, empleándose los recursos para obras públicas como caminos y el fomento a las escuelas. Eventualmente fue necesario también cubrir algunos imprevistos como fue el caso de la epidemia de viruela que azotó a Santa Fe en 1802.

\section{Fuentes}

\section{Fuentes Primarias}

\section{Archivos}

Archivo General de la Nación (AGN), Sección República, Fondos: Eclesiásticos, Empleados Públicos-Cartas, Historia, Ministerio de Instrucción Pública, Miscelánea, Peticiones-Solicitudes, Reales Cédulas y Órdenes.

Archivo Histórico de Medellín (AHM), Fondo Concejo de Medellín.

\section{Publicaciones periódicas}

Correo Curioso de Santafé de Bogotá, Santafé de Bogotá, 1801.

El Eco de Antioquia, Medellín, 1822.

Gaceta de Caracas, Caracas, 1819.

Gaceta de Cartagena de Colombia, núm. 194, Cartagena, 1821-1825

Gaceta de Colombia, Bogotá, 1821.

\footnotetext{
${ }^{65}$ Lozano Armendares, Teresa, Op. Cit., p. 164.

${ }^{66}$ Después del proceso de Independencia, disminuyó ostensiblemente en Colombia la presencia del Estado en el área de la caridad y la asistencia pública, vacíos que fueron cubiertos por la Iglesia y las instancias privadas. Hayley, Froysland. "Caridad, asistencia pública y moralización: el mantenimiento de un orden social, paternalista y jerárquico en Colombia, 1850-1940”, en Memoria y Sociedad, vol. II, núm. 4, Bogotá, Pontificia Universidad Javeriana, 1997, p. 156.
} 
Gazeta de la ciudad de Bogotá, Bogotá, 1820-1821.

Gazeta Ministerial de Cundinamarca, Santafé de Bogotá, 1812.

Papel Periódico de Santafé de Bogotá, Santa Fe, 1792-1793.

Libros

Actas de la Junta Municipal de propios de Santa Fe de Bogotá, vol. I-III. Bogotá: Ediciones del Concejo, 1938.

Caballero, José María. Diario de la Patria Boba. Bogotá: Editorial Incunables, 1986.

Castillo y Rada, Rafael del. Memorias que el Secretario de Estado y del Despacho de hacienda presenta al Congreso de Colombia sobre los negocios de su Departamento. Bogotá: Imprenta del Estado, por Nicomedes Lora, 1823.

Enciclopedia Universal Ilustrada Europeo-Americana, t. XXXI. Barcelona: Hijos de J. Espasa Editores, 1933.

Groot, José Manuel. Historia Eclesiástica y Civil de Nueva Granada, t. II. Bogotá: Imprenta a cargo de Foción Montilla, 1869.

López Domínguez, Luis Horacio (comp.). De Boyacá a Cúcuta. Memoria Administrativa, 1819-1821. Bogotá: Biblioteca de la Presidencia de la República, 1990.

Ortega Ricaurte, Enrique. Cabildos de Santafé de Bogotá, cabeza del Nuevo Reino de Granada 1538-1810. Bogotá: Ministerio de Educación Nacional, 1957.

\section{Fuentes secundarias}

\section{Libros}

Bushnell, David. El Régimen de Santander en la Gran Colombia. Bogotá: El Áncora Editores, 1985.

Guimerá, Agustín (ed.). El Reformismo Borbónico: una visión interdisciplinaria. Madrid: Alianza Editorial, 1996.

Jiménez Meneses, Orián. El frenesí del vulgo. Fiestas, juegos y bailes en la sociedad colonial. Medellín: Universidad de Antioquia, 2007.

Lucena Giraldo, Manuel. 82 objetos que cuentan un país. Una historia de España. Madrid: Editorial Taurus, 2015.

Mayorga García, Fernando. La Audiencia de Santa Fe en los siglos XVI y XVII. Bogotá: Instituto Colombiano de Cultura Hispánica, 1991. 
Los inicios del juego de lotería en Colombia: entre la suerte, el control social...

Vargas Lesmes, Julián. Historia de Bogotá, ts. III-IV. Bogotá: Salvat-Villegas Editores, 1989.

Viqueira Albán, Juan Pedro. Relajados o reprimidos. México: Fondo de Cultura Económica, 1987.

\section{Capítulos de libros}

Meisel Roca, Adolfo, "La crisis fiscal de Cartagena en la era de la Independencia, 1808-1821", en Calvo Stevenson, Haroldo y Meisel Roca, Adolfo (eds.). Cartagena de Indias en la Independencia. Cartagena: Banco de la República, 2011.

\section{Artículos en revistas}

Alonso Cifuentes, Julio César y Gallego Londoño, Ana Isabel. "Concesión del monopolio de juegos de apuestas y azar en el Valle del Cauca", en Estudios Gerenciales, vol. 26, núm. 116, 2010.

Bendezú Velarde, José. "Loterías: una alternativa para financiar los fondos para la educación”, en Revista de la Facultad de Ciencias Económicas, vol. V, núm. 19, 2001.

Cordoncillo, José María. “La Real Lotería en Nuevas España”, en Anuario de Estudios Americanos, vol. XVIII, núm. 196, 1961.

Hayley, Froysland. "Caridad, asistencia pública y moralización: el mantenimiento de un orden social, paternalista y jerárquico en Colombia, 1850-1940", en Memoria y Sociedad, vol. II, núm. 4, 1997.

Lozano Armendares, Teresa. "Los juegos de azar: una pasión novohispana?”, en Estudios de Historia Novohispana, vol. XI, núm. 11, 1991.

Pardo, Andrés y Visadias, Francisco José. "Plan fiscal y económico para la provincia de Antioquia (1782)", en Anuario Colombiano de Historia Social y de la Cultura, vol. 9, núm. 1979.

Pita Pico, Roger. "Censuras y regulaciones a los juegos de albur en el Nuevo Reino de Granada, siglo XVIII”, en Boletín de Historia y Antigüedades, vol. CI, núm. 858, 2014. 